\title{
Oncogene KIT
}

National Cancer Institute

\section{Source}

National Cancer Institute. Oncogene KIT. NCI Thesaurus. Code C18348.

Cloned cancer gene for Familial gastrointestinal stromal tumors (GIST), KIT protooncogene encodes a putative transmembrane receptor tyrosine kinase for stem cell factor and is critical in the development of pluripotent hematopoietic stem cells, migrating embryonic melanoblasts, and primordial germ cells. The human protooncogene is located at $4 \mathrm{q} 12$. 